\title{
SCENARIO-Gespräch mit Renate Breitig, Gründerin von TUSCH, Berlin
}

\section{Renate Breitig}

Im Juni 2011 führte Manfred Schewe ein Gespräch mit Renate Breitig, der Gründerin von TUSCH (Theater und Schule) Berlin.

TUSCH vereinigt als Kooperations-Netzwerk für Kulturelle Bildung im Bereich Theater 123 Berliner Schulen und 36 Berliner Bühnen. Innerhalb dieses Netzwerks regt TUSCH Begegnung und Austausch an und unterstützt dies mit einem Newsletter, künstlerischen Werkstattangeboten, Fortbildungen für Lehrer/innen und Künstler/innen, sowie Theaterprojekte und -besuche für Jugendliche aller TUSCH-Schulen.

Klicken Sie hier, um das Gespräch hören.

Nähere Informationen finden sich unter: www.tusch-berlin.de 